\title{
Acting on uncertainty: real-life mixtures of endocrine disrupting chemicals
}

\author{
Nadav Even Chorev $^{1} \cdot$ Giuseppe Testa $^{1,2}$
}

Published online: 28 April 2020

(C) The Author(s) 2020

\begin{abstract}
Exposure to multiple synthetic chemicals is a permanent feature of modern life. Many of these chemicals are suspected to disrupt endocrine systems of humans and animals. Endocrine disrupting chemicals (EDCs) act at very low concentrations and non-linearly, defying mainstream single-substance chemical regulation. Here we provide an analysis of findings from the first phase of the European Horizon2020-funded "EDC-MixRisk" project as a case of contemporary life-science enterprise, which addresses health-risks related to real-life exposure to mixtures of EDCs. Real-life EDC mixtures were inferred in the project from biological samples taken from pregnant women in a large epidemiological study that followed up their children over several years across major health domains; responses to these mixtures were then experimentally identified, and based on these findings, mixture risk assessment models were developed. The project consequently advocated for European chemical regulation more attentive to real-life exposure. Locating it within historical and sociological analyses of chemical exposure and within the European chemical political context, we argue that scientific uncertainty related to real-life EDC mixture exposure enables a form of epistemological approach and scientific activism, simultaneously in continuity with, and in break from, mainstream toxicology. In a chemically polluted world, this kind of science still occupies a place in the tension between public health and market-oriented regulation.
\end{abstract}

Nadav Even Chorev

nadav.evenchorev@ieo.it

Giuseppe Testa

giuseppe.testa@ieo.it

1 High Definition Disease Modelling Lab: Stem Cell and Organoid Epigenetics, Department of Experimental Oncology, IEO, European Institute of Oncology IRCCS, Via Adamello 16, 20139 Milan, Italy

2 Department of Oncology and Hemato-Oncology, University of Milan, Milan, Italy 
Keywords Endocrine disrupting chemicals - Real life $\cdot$ Chemical regulation · Uncertainty $\cdot$ Science activism

\section{Introduction}

The ubiquitous, constant exposure to multiple environmental chemicals has become a fixed feature, the 'white noise' of modern life and part of the living experience of many populations (Bergman et al. 2013a, b; Murphy 2006). Rather than being exposed to relatively few, highly toxic substances, exposure is now characterized as a blanket of thousands of chemicals found in low doses, coming from air, water, food and components of numerous consumption products (Kortenkamp 2014). Exposure to synthetic chemicals, their effects on humans, animals and the environment, and its social and political repercussions have been documented and analyzed in the life sciences, toxicological sciences, social and policy sciences alike. Despite decades of efforts at regulating chemical hazards and risks, exposure has not been reduced (Boudia and Jas 2014, p. 11; Langston 2010). In the European Union alone, chemical production in 2017 totaled about 290 million tons, about $75 \%$ of which was classified as hazardous to health (Eurostat 2018).

The number of existing chemical mixtures in the environment poses a formidable challenge if chemical regulations are to become attuned to real-life exposures. While the current regulatory paradigm takes a substance by substance approach, pesticides, cosmetic products and industrial chemicals contain numerous substances that may interact with one another. In many cases, the composition of mixtures is unknown. Moreover, once released into the environment, mixtures themselves do not remain static: they change over time while their different constituent substances degrade in different ways, interact with local conditions and further mix with additional emissions (Kienzler et al. 2014, p. 5).

A significant proportion of these mixtures consists of chemicals which are suspected to have properties that disrupt the functioning of the endocrine systems of humans and animals, known as Endocrine Disrupting Chemicals (EDCs). These man-made chemicals - among them phthalates, phenols, Per- and polyfluoroalkyl substances (PFAS) and Polychlorinated biphenyls (PCBs) - originate and are present again in numerous consumer and industrial products. The investigation of EDCs has been the focus of increasing scientific activity since the early 90s (Colborn et al. 1993; Damstra 2002; DeRosa et al. 1998; Vos et al. 2000). Exposure to individual EDCs has been associated with impaired development in humans. One of the wellknown examples is Bisphenol A (BPA), a common substance in plastic products including baby bottles, CDs, food containers and many more. Exposure to BPA has been associated with hormonal effects in experimental models, in turn linked to adverse health effects in humans (Calafat et al. 2008; Vandenberg et al. 2007). However, the regulation of BPA is a subject of continued debate in various bureaucratic agencies in both the USA and Europe (Vogel 2009; Beronius et al. 2010).

Chemical policy in western countries has turned to science to provide justification for regulatory actions. Yet scientific uncertainty in establishing risks related to chemical exposure has been exploited by different stakeholders: industry players 
have used uncertainty to deny causal relations between exposure to chemicals and health effects, while environmental and patient groups relied on uncertainty to push for a precautionary action. This has been discussed already by Brickman, Jasanoff and Ilgen (1985). How can this underlying uncertainty, as a matter of scientific and public health concern, be understood in relation to the complexity of real-life exposure to multiple EDCs? What scientific forms are available for acting on matters of endocrines disruptors?

To shed light on this question, we examine the case of the EU Horizon2020funded project titled "EDC-MixRisk: Integrating Epidemiology and Experimental Biology to Improve Risk Assessment of Exposure to Mixtures of Endocrine Disruptive Compounds" (European Commission 2019). We explore this multi-partner, large-scale scientific project, which took place between May 2015 and April 2019, as an attempt to make sense of the uncertainty of exposure to mixtures of EDCs. The project used the large mother-child cohort "Swedish Environmental Longitudinal, Mother and child, Asthma and allergy" (SELMA, Bornehag et al. 2012) epidemiological study, to derive chemical mixtures to which the studied population was actually exposed. Chemicals present in the pregnant women' bodies were identified using chemical-analytical methods and statistically associated with neurological, metabolic and sexual developmental adverse effects in the exposed mothers' children. The effects of exposure to these mixtures were then validated on both in vitro and in vivo experimental models. Based on its findings, the project then took an active stand in a further attempt to translate the evidence into mixture risk assessment tools and advocate for an improved EU chemical regulation. This approach could potentially turn current toxicological paradigm on its head: given the reality of a toxic environment, regulation should be based on bottom-up, real-life exposure to multiple chemicals - among them EDCs and the uncertainties they encompass - rather than on data supplied by producers on each separate chemical. The EDC-MixRisk project did not seek to validate some risk assessment testing tool for a particular substance. It aimed to set benchmarks, based on exposure patterns not determined in advance but inferred from reality, against which producers could test the mixtures they manufacture.

In historical terms, the EDC-MixRisk project represents a continuity along many dimensions with mainstream toxicological science and its role in regulations of chemical exposure. As has been examined in historical and sociological studies of chemical exposure, science has justified its intervention in the politics of chemical regulation based on its claim for objectivity (Frickel 2004, pp. 122-123; Murphy 2006, p. 119). The question in this context therefore is in what terms does the EDCMixRisk represents a deviation from normal toxicological science? How does the project construct itself as different from other endeavors in the field of toxicological science?

We show that the attempt to make sense of the exposure to mixtures of EDCs serves as a motivation to construct science differently than is accustomed in the context of European-sponsored chemical toxicology research. The project, we argue, plays on the tensions entailed in the uncertainty of EDC mixtures while moving from the epidemiological and experimental scales of exposure to its discursive scale. This takes place in a political context where opponents of chemical regulation have 
turned from discrediting environmentalism and public health, to undermining regulation itself (Oreskes and Conway 2010, p. 217), and in which the status of the scientific fact in not as certain as before (Jasanoff and Simmet 2017). We will first locate our analysis in the larger context of historical and sociological literature on chemical exposure, to show where our analysis contributes to this line of research. Taking a constructivist methodological approach to this case, we further locate the case in the political context of the controversy over EDC regulation in the European Union. We focus on how the uncertainty of real-life EDC mixtures is engaged with epidemiologically and experimentally in the project. We argue that scientific activism is represented here not only in how the project purports to provide input for European chemical regulation, but in how the science itself is organized in the project. By shedding light on the interplay of scientific activism and chemical exposure uncertainty, we posit the analysis on the larger context of continuity and change in the relations of science with regulation of environmental health effects.

\section{Chemical Uncertainty and Scientific Activism?}

The problem of exposure to synthetic chemicals is inextricable from modernity. Underlying this modernistic discourse is an epistemic perception that views entities-chemicals, humans, the environment, categories-as discrete and separate from one another. With modernity, environment became an entity in itself, bodies became discrete from the environment and self from exposure (Roberts 2017). Such modern understanding caries certain implications for chemical exposure, particularly exposure to endocrine disruptors, as can be identified in the environmental historical and sociological literature on the subject.

Underscoring the regulation of chemicals in the twentieth and twenty-first centuries in Europe and the USA is the dynamic between the modern imperatives of protecting the population through public health, and ensuring economic growth and competitiveness (Boudia and Jas 2014). During most of the decades of the twentieth century, maintaining this balance was supported by modernist faith in scientific expertise and technological progress. Chemicals became to be viewed as largely discrete entities in themselves, amenable to understanding and control by modern western institutions (Murphy 2006, p. 5). Regulators have come to rely on systems of categorization that classify chemical according to their molecular structure, registered in standardized data bases (Hepler-Smith 2019). Following from this, the dominant regulatory approach is based in substance-to-substance regulation. Toxicological science provides the means and tools to identify the causal chains that explain the connection between exposure to a chemical and the risk of its adverse effect. If such a connection can be identified, it is possible to measure the extent of exposure and determine a threshold below which exposure can be considered safe, according to "the dose makes the poison" approach (Vogel 2008).

Yet uncertainty is part and parcel of modernity too. While it is not unique to modernity, uncertainty came to be understood, constructed, manufactured and reconfigured as such with the rise of logic of risk and risk management (Ewald 2002; Beck 2006). After WWII, chemical production has reached unprecedented 
scales, while regulation has been slow to respond (Boudia and Jas 2014). Exposure has become global, ubiquitous and constant (Liboiron et al. 2018). In these conditions, if bodies are imbued in a chemically laden environment, the separation of bodies from chemicals and the environment is challenged (Hepler-Smith 2019). Regulation of chemicals on a segmented, substance-to-substance basis stands in contrast to the embodied, lived experience of daily exposure to multiple chemicals (Boudia et al. 2018; Creager 2018; Hepler-Smith 2019; Langston 2010; Mukherjee 2016). As Linda Nash has put it, "debates over chemicals and their regulation are, at root, debates about the relationship between bodies and the environment" (2008, p. 651). The literature discusses several aspects of uncertainty that have undermined modernist dichotomies and the scientific basis of chemical regulation over the past few decades. These have included the difficulty in demonstrating how each chemical acts when interacting with organisms (their 'modes of action'), the ability to extrapolate from exposure effects seen in laboratory models to human effects and more generally the ability to infer from one organism to another (Frickel 2004, p. 103). The temporal delay between cause-chemical exposure-and the manifestation of effect-the associated human health problems-further compounds this problem (Langston 2014; Oreskes and Conway 2010, p. 221).

Endocrine disrupting chemicals pose particular challenges in this respect. These chemicals have been found to exert effects on endocrine systems in very low concentrations. The concept of low-level effects originated already in the 1970s (Boudia 2014). It took gradual hold and has also been contested since then. On the one hand, low-dose exposure makes it difficult to differentiate experimentally between natural and synthetically induced hormonal processes with the organism. On the other hand, if these chemicals do affect endocrine systems, this negates the concept of safety thresholds: already very low levels of exposure to EDCs poses risk (2014, p. 97). In other words, EDCs challenge the notion at the basis of current regulation, according to which the effect of chemical exposure is a function of the extent of exposure (Vogel 2008, p. 671).

Instead of the extent of exposure, the timing of exposure becomes important. While the adult system is able to compensate to external environmental 'insults', such exposures may leave a lasting effect on the systems of the developing fetus (Mansfield 2017; Vogel 2008). The effects on the developing fetus may manifest only years later, and again making it difficult to relate cause to effect (Langston 2010, 2014). In addition, real-life entails exposure to multiple chemicals simultaneously. When in mixtures, EDCs can act synergistically, producing an effect larger the sum of effects of compounds together, challenging the possibility of pinpointing the causal element in the mixture (Rowe Davis 2008).

In light of all these aspects of uncertainty, it becomes a problem to predict hazard and build risk management measures upon it (Rowe Davis 2008). Any indicator of hazard becomes a potentiality (Creager 2018). Acting on such uncertainty may take on different directions. It can be used as a basis for pushing for a precautionary regulatory action (Vogel 2012; Langston 2014). The precautionary principle has been incorporated for years in European chemical regulation. The burden of proof' under the precautionary principle in the EU means that it is sufficiently necessary for the concerned parties to demonstrate that there is some likely danger. The 
scientific knowledge upon which precaution is based identifies danger yet also demonstrates that risk cannot be determined with sufficient certainty (European Commission 2000). However, uncertainty has been exploited by the chemical industry as well as regulators both in Europe and the US to undermine science, particularly on endocrine disruptors, to argue that the presence of synthetic chemicals is necessary, that risks of chemical exposures are uncertain, and that they are therefore "events that one cannot do something about" (Murphy 2006, p. 10). Thus, in the long-term balance between protecting public health and ensuring economic growth, chemicals industries and market-oriented regulators have thwarted chemical policy in favor of the latter (Boudia and Jas 2014).

What is the role of science given this failure to regulate chemical exposure? A permanently polluted world means that acting within it should be based on the determined condition of entanglements of porous bodies and chemically polluted ecologies. Liboiron et al. (2018), as well as Shapiro (2015) and Murphy (2006), have highlighted forms of political action from below, with and against slow-occurring chemical conditions. Although within the institutionalized power relations of chemical policy, science has gradually moved to a more confrontational position versus industry and regulators (Boudia and Jas 2014), Liboiron and his colleagues view it, rightly so, as a "science-as-usual" that takes part in the dominant ways of defining toxicity (2018, p. 337). The two forms of action do not exclude each other, yet given that political action is always contested, by scientific movements or other actors (Tarrow 2011), we focus here on the EDC-MixRisk project as a case that shows that science can still have the potential to act other than "as-usual". The EDC-MixRisk project provides an example of using conventional scientific means, displaying continuity with existing practices, to construct an unconventional way of doing science (Frickel 2004). Mostly, as we argue, since it engages with the contested, uncertain problem of exposure to EDC mixtures. By this, it deviates to an extent from mainstream scientific practices in the field.

\section{Methodology}

The account we provide here is an interpretation of the first phase of the project. Principally, our aim is "to understand the interplay of material and epistemic dynamics" (Webster 2012, p. 5) within it. By providing a narrative of the first phase of the project, we shed light on dimensions of scientific uncertainty of chemical exposure, and on how the epistemic understanding of this uncertainly facilitates a specific form of scientific activism. For this purpose, we took a case study strategy, to understand the EDC-MixRisk project as a phenomenon taking place in a specific context (Yin 2014).

Our methodological approach consists of two aspects. First, the account is provided by a reflexive analysis drawn from our dual position of both participants and observers (Maharaj 2016, pp. 117-121). In addition to the epidemiological, experimental and risk assessment modules, the project program also provided for a scholarly analysis of its "ethical and societal implications" (European Commission 2015, p. 133). Vested with both these tasks, we provide context-dependent observational 
data, all the while taking into account our own interaction with this same context (Ralph et al. 2015). Our dual position reflects "a tension between engaging with the world as we find it and intervening in debate" (Hine 2007, p. 654). We build on this tension to bring to light epistemic dynamics characterizing the project.

The second aspect consists of framing this account within a discursive context, drawn from the description of the project which is part of its Horizon 2020 grant agreement and additional texts produced by the project. The project description serves as a formal basis, setting the scientific and normative justification for the project. These texts were analyzed based on the approach offered by Frickel of collective action frames in his analysis of the emergence of genetic toxicology as a scientific movement $(2004$, p. 85). Frickel, in turn, elaborates this concept as formulated by Benford and Snow (2000), and by Entman (Entman 1993). This conceptualization is rooted in constructivist sociological paradigms. More of a lose set of ideas than a formal ideology (Frickel 2004, p. 85), collective action frames can be viewed as ways for scientists to construct meaning about novel ideas in the context of action: “... an active, processual phenomenon that implies agency and contention at the level of reality construction" (Benford and Snow 2000, p. 614). More specifically, to frame is to "...select some aspects of a perceived reality and make them more salient in a communicating text, in such a way as to promote a particular problem definition, causal interpretation, moral evaluation, and/or treatment recommendation" (Entman 1993, p. 52, emphasis in the original). Locating these aspects in the text was performed using content analysis to emphasize moments of contention, definition of problems and calls for action (Krippendorff 2018; Perakyla and Ruusuvuori 2018).

\section{Setting the Political Context}

The EDC-MixRisk project was conceived, initiated and took place amid an unfolding controversy in the EU, on the ways to identify chemicals as EDCs and define their ontological status. At the center of this controversy stood, the question of the causal relations between exposure to chemical suspected as EDCs and adverse health effects: choosing between a precautionary path, based on associations, partial knowledge and uncertainty, and a risk management path, based on lengthy procedures of demonstrating causality, entailed high stakes for the chemical industry.

The status of endocrine disruptors has been debated in the EU since the late 1990s (Vos et al. 1999; European Commission 2001), involving EU institutions, groups of scientists, NGO's and industry organizations. The European regulation on Biocides of 2012 (The European Parliament and The Council) required that the Commission adopt an act specifying scientific criteria to identify chemicals as endocrine disruptors by December 2013. Instead of adopting such an act, under alleged industry pressure, the Commission opted for a process to evaluate the impact of the different possible alternatives for such criteria (Scholz 2016, p. 6). In 2014, Sweden, supported by the European Parliament, appealed to the European General Court, which ruled that the Commission has breached its obligations (2015). The Impact Assessment was nevertheless carried out, its conclusions (European Commission 2016b) served 
as a basis for formulating draft acts on the criteria by the Commission's Standing Committee on Plants, Animals, Food and Feed. Draft acts defining the criteria were published beginning September 2016 (European Commission 2016a).

In parallel, the rolling controversy over EDCs and their effects blurred the lines between the scientific and the political in the EU chemical regulation field. In 2013, a group of toxicology journals' editors published an open letter titled 'Scientifically unfounded precaution drives European Commission's recommendations on EDC regulation, while defying common sense, well-established science and risk assessment principles" (Dietrich et al. 2013). In this text they disputed evidence on low-dose and non-linear ('non-monotonic') patterns of response to EDC exposure in humans. As mentioned, these characteristics undermine the concept of safety thresholds (Bergman et al. 2013a, b; Langston 2014; Vandenberg et al. 2012). Yet Dietrich and his colleagues disputed this point exactly, arguing that "“"endocrine disruption" is not a toxicologically defined [health] endpoint" (2013, p. 2110) and that European regulation of EDCs cannot be built on an assumption of no thresholds while regarding experimental evidence as relevant to human health. Two commentaries published that same year argued against this position, pointing to a body of research that substantiates low-dose effect of EDCs (Bergman et al. 2013a, b; Gore et al. 2013). While Dietrich took part in formulating a scientific consensus statement on how to identify EDCs and on the need to regulate them (Solecki et al. 2016), he later gave a presentation to the European Parliament, arguing that synthetic EDCs pose no risk and cannot be causally associated to human health problems at current exposure levels: "EDCs follow a concentration response principle, with a threshold" (Dietrich 2018, p. 14). These arguments were again contrasted in a report to the European Parliament by two endocrine disruption researchers (Demeneix and Slama 2019, pp. 102-106). Among the authors of the publications in support of evidence on human effects of EDCs were some of the investigators involved in the EDC-Mix Project.

As drafts of the criteria were debated in the Commission and gradually published, environmental groups such as Pesticides Action Network Europe, Health and Environment Alliance, CHEM Trust and EDC-Free Europe have raised protests. In its response to the Commission's public consultation on the criteria, The Endocrine Society, a US-based endocrinology scientific society, claimed that "the Commission has proposed criteria to identify EDCs requiring a level of certainty that are nearly unachievable scientifically" (Laakso 2016). An open letter from a group of scientists similarly argued that "the new draft has replaced what was unequivocally a too-high burden of proof with an ambiguous burden of proof" (Whaley et al. 2016). Again, among the signatories of this letter were investigators in the project.

The criteria were based on a widely accepted definition of EDCs formulated by the International Programme on Chemical Safety of the UN's World Health Organization, and in which one of the EDC-MixRisk project investigators took part. According to this definition: "An endocrine disruptor is an exogenous substance or mixture that alters function(s) of the endocrine system and consequently causes adverse health effects in an intact organism, or its progeny, or (sub)populations" (Damstra et al. 2002, p. 1). Despite the open-endedness of this definition (endocrine disruptors are exogenous substance that alter the function of the endocrine system), 
the criteria finally adopted stressed the need to demonstrate causality. The delegated act specifying the criteria to be annexed to the Biocidal Products Regulation (The European Parliament and The Council 2012) was adopted on September 2017 and another, specifying identical criteria, was adopted on April 2018 to be annexed to the Plants Protection Products Regulation (The European Parliament and The Council 2009). Thus, for a substance to be considered as having endocrine disrupting properties, it must fulfill three conditions:

(1) it shows an adverse effect in an intact organism or its progeny, which is a change in the morphology, physiology, growth, development, reproduction or life span of an organism, system or (sub)population that results in an impairment of functional capacity, an impairment of the capacity to compensate for additional stress or an increase in susceptibility to other influences; (2) it has an endocrine mode of action, i.e. it alters the function(s) of the endocrine system; (3) the adverse effect is a consequence of the endocrine mode of action. (European Commission 2017).

In the context of this conflict between causality and uncertainty of the effects of exposure to EDCs, the EDC-MixRisk project chose to tackle the side of uncertainty, complicated further by engaging with real-life exposure to multiple EDCs.

\section{The EDC-MixRisk Project as a Paradigm of 'Real-Life' Science}

The idea of no safe thresholds, as discussed by Brickman, Jasanoff and Ilgen, entails the "...incompleteness of the data and the apparent variations in individual and species susceptibility" (1985, p. 208) to adverse health effects due to carcinogenic chemical exposure. In this sense, the EDC-MixRisk project engaged in scientific uncertainty that has pervaded chemical regulation in Europe and the US for decades. However, rather than seeking to ascertain the existence or non-existence of thresholds or take a position on the EDC threshold controversy (Solecki et al. 2016, p. 1005), the project took on board the very uncertainty of thresholds for EDCs by choosing to identify levels of effects of EDC mixtures based on real-life exposure patterns. Replacing a regulatory style of thought with a real-life mixture-oriented epistemic approach structured the set-up of the project as active in both science and its intervention in the public sphere.

Against this background, the EDC-MixRisk project formulated its overarching goal in political terms. It was “...designed to promote the use of safe chemicals for the next generation" (European Commission 2015, p. 86). This intention was then formulated as the objective "...to move forward and meet the societal need of improved decision making regarding human exposure risks to mixtures of anthropogenic chemicals over the whole life span...the project will determine and assess the risk for multiple adverse health outcomes based on molecular mechanisms involved, after early life exposure to complex mixtures of endocrine disrupting chemicals" (2015, p. 131). The problem the project sought to respond to was thus formulated in terms of real-life exposure: 
Health risks linked to EDC exposure may have been significantly underestimated because research conducted in this field almost exclusively have used a compound-by-compound approach. In reality, we are exposed to mixtures of chemicals...To adequately address the real life situation in risk assessment, an important step is therefore to relate multiple EDC exposure to multiple health outcomes in different health domains. There is currently no widely agreed system for evaluating the strength of evidence of associations between exposures to multiple chemicals (including EDCs) and multiple adverse health outcomes (European Commission 2015, p. 131).

Linking exposure to EDCs mixtures with "multiple adverse health outcomes" was interpreted in regulatory terms as the project adopted the definition of EDCs provided by the International Program on Chemical Safety of the WHO. One of its defined tasks was therefore to "ensure the workability" of this definition. A late project report on this task detailed how this definition was understood:

Since these [EU] criteria were not available at the start of EDC-MixRisk, we took the IPCS/WHO definition 1 from 2002 as a benchmark. This widely accepted definition of an EDC requires that the following knowledge is generated: (1) an endocrine mode of action, (2) an adverse outcome in vivo, and (3) a connection between 1 and 2 (Ruden and Bui 2019, p. 2).

In other words, the project set out to directly engage with the problem of demonstrating causality. To tackle this challenge, the project advanced in four tiers across scales of evidence and intervention, outlined as follows: "The overall concept is to integrate research from three scientific modules of relevance to the aims of the study: epidemiology, experimental biology and risk assessment" (European Commission 2015, p. 132). These three different modules, or scales, are represented in project documents in a hierarchical fashion of separate units which feed into each other (Fig. 1).

Within this representation, the actual movement is circular, from the characterization of real-life exposure, back to intervening and advocating for regulation that would affect the permanently EDC-polluted European population. This cycle is not a determinist structure. Alternatives can be imagined, such as research projects that aim directly to develop regulatory chemical testing tools (see review in Bopp et al. 2018). However, the set-up of the EDC-MixRisk project reflected its 'real-life' epistemology. Thus, the "regulatory and society impact" are construed as the main justification of the project, although the translation into social intervention became possible only after other scales played out.

The first scale, the epidemiological one, “.... will be used in order to identify EDC mixtures, with impact on the three health domains leading to adverse health outcomes..." (2015, p. 132). The product of this scale was a list of EDCs identified on the basis of an analysis of the Swedish SELMA pregnancy cohort study. The study conducted biochemical analyses of serum and urine samples given by pregnant women to understand their uncontrolled, day-to-day exposure patterns. The children of these women were examined at birth and then in intervals until the age of seven, to identify adverse effects on metabolic, neurological and sexual development 
Fig. 1 Scientific project workflow (By kind permission of Prof. Åke Bergman, Stockholm University; see also (Even Chorev and Testa 2019)

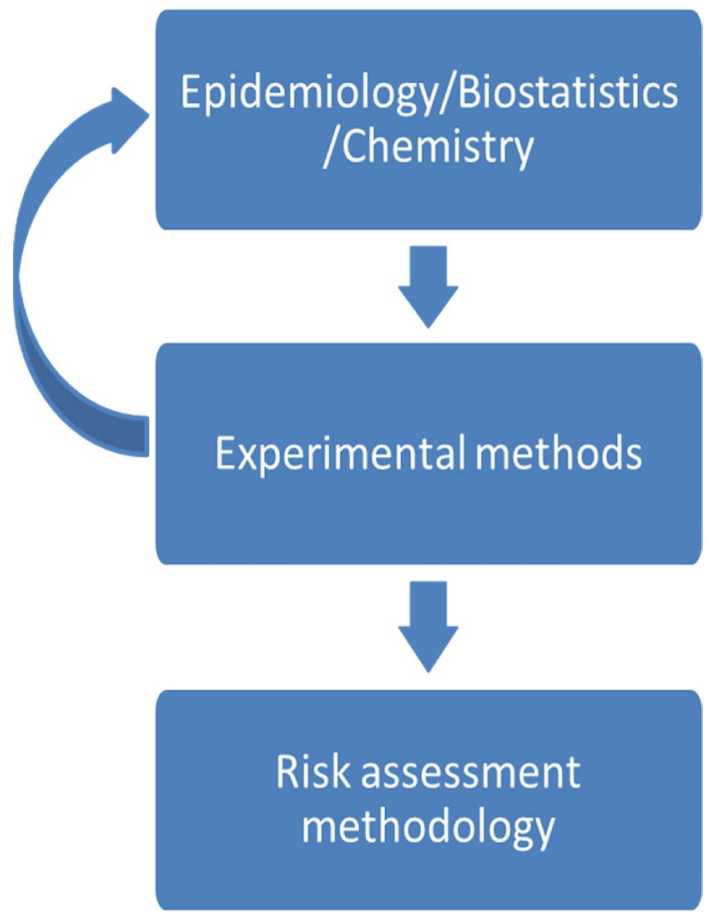

processes. These were measured respectively through birth weight levels, language development and an indicator for reproductive development termed anogenital distance. The search for chemicals to which the women were exposed was made initially for phthalates and phenols suspected in the literature as endocrine disruptors. That is, the search did not start from a complete 'tabula rasa' assumption. However, list of candidate chemicals from these two categories was not completely predetermined either. It was composed on the basis of what was found eventually in the biological samples. The effort was then made to cover additional classes of chemicals (Bornehag et al. 2012). In this way, the idea of real life is embodied here in uncontrolled exposure. Chemicals enter the bodies of women, circulate through their biological systems, alter them, and these alterations may be passed on to their children (Alavian-Ghavanini and Rüegg 2018). Chemicals are thus engrained enough to affect adverse health outcomes in these women's children, yet distinct enough to maintain the status of 'exogenous materials' that can be isolated and measured as relevant variables to be experimentally tested in subsequent phases of the project.

After outlining the real-life exposure patterns of the women in the SELMA study, the next step was to construct exact recipes of ingredients and quantities for mixtures of chemicals associated with the adverse effects in the three health domains. This step consisted of two stages. The first was to find which chemicals out of the emerging exposure patterns were those associated with adverse health outcomes. The analysis of the mothers' urine and serum identified forty-one compounds suspected as instigating the endocrine-related adverse effects in their children and that were 
at levels that could be quantified (Bergman et al. 2019). The compounds included phthalates, phenols, PFASs and PCBs. From among these forty-one compounds, a statistical strategy termed Weighted Quantile Sum (WQS) regression (Carrico et al. 2015) was used to identify those chemicals which were associated with adverse outcomes in the children. Using this strategy, it was possible to establish a list of eleven chemicals to be tested experimentally in the first phase of the project.

The next step after pinpointing the suspected compounds was to estimate the extent of exposure to each compound. For this purpose, it was necessary to evaluate the daily intake of each such chemical by the pregnant women. This was important in order to determine mixing ratios for the mixtures for each health domain. The daily intake was estimated from the proportion of metabolized compounds found in the urine analyses and those measured in the serum. The mixtures were then prepared and validated by chemistry laboratories in Sweden and Finland. These two stages allowed to prepare three mixtures that mimic the real-life environmental exposure. Defining the composition and proportions of chemicals in each mixture, and later preparing mixtures in a chemistry lab, was a key moment that established an epistemology on which the project is founded: to infer EDC mixtures from reallife scenarios.

Real-life contingency and scientific uncertainty regarding how EDCs operate were thus embodied in these mixtures and carried on into the molecular-experimental scale. On this scale, experimental exposure of “...various animal and cell models will uncover molecular mechanisms underlying effects seen in the epidemiological studies. Modes-of-actions underlying effects of identified EDC mixtures will be determined with a focus on finding molecular initiation events and understanding adverse outcome pathways" (European Commission 2015, p. 132). The results of this scale served to close the circuit back to the attempt to influence the future course of life through improved chemical regulation.

The experimental models were meant to simulate the animal and human dynamic biological processes of change and development in the three health domains (neurodevelopment, metabolism and growth and sexual development) and the potential interference to these processes by chemicals. The molecular basis of the effect instigated by the experimental exposures to EDC mixtures was identified by measuring various indicators, both molecular and phenotypic: from changes in the expression of genes in cell models to changes in mobility patterns of exposed animal models, both compared with unexposed models. These models included, for example, stem cell lines, brain organoids (three-dimensional approximations of the developing human cortex), fetal neural tissues, and model organisms (zebrafish, tadpoles and mice) (Birgersson et al. 2017; Kitraki et al. 2016). In a manner similar to the overall set-up of the project as described above, the molecular scale too was already built around concepts used in the chemical regulation field. Mode-of-action, molecular initiating events (MIEs) and adverse outcome pathways (AOPs) are conceptual frames elaborated by the OECD (2018) and applied to describe the path from the molecular interaction all the way to adverse effects at the level of populations of organisms (Perkins et al. 2015).

To demonstrate how real-life mixtures were used to simulate effects in biological models, we use an example of one instance of the experimental molecular scale. We 
followed the attempt to examine the effects of an EDC mixture on the neurodevelopment health domain as it was originally performed in a lab of one of the partners in the project. We provide this account as practitioners and observers. Specifically, three types of models were exposed experimentally to the mixture of chemicals, inferred in the SELMA study as associated with low language delay, the indicator of neurodevelopmental problems. These models, in turn, were seen to represent human neurological development: stem cells differentiated into neural cells (of a type called NGN2, Zhang et al. 2013), stem cells differentiated into brain organoids (Amin and Paşca 2018; Caporale and Testa 2019; Marelli and Testa 2019), and samples of fetal brain tissues obtained from elective abortions (Birgersson et al. 2017).

The overall objectives of the experiments, including those on neurodevelopment, were stated in the formal project description:

It is essential to understand the molecular mechanisms behind the adverse health effects in order to:

i) prove a causal link between exposure and outcome,

ii) develop biomarkers of exposure and risk of disease, and

iii) vision counteractive measures to prevent such adverse effects from happen-

ing (European Commission 2015, p. 139).

If previously the overarching goal of the project was formulated as engaging with causality, the ambition articulated here is no less than to dispel ("prove a causal link") the causal ambiguity of exposure to EDCs and their relations to adverse health outcomes such as autism and cognitive disorders. This proof, in turn, will be mobilized to serve other purposes ("counteractive measures to prevent such adverse effects from happening"). This third objective was to be realized through the regulatory scale, reconnecting to the project's larger goal. The crucial link here is exposure: first, exposure of populations of real women and their children to real mixtures, and then, simulating this exposure on experimental models.

Specifically, the goal of neurodevelopmental experiments was defined as "...capturing human-specific EDC-dependent neurodevelopmental malfunction in the dish" (2015, p. 152). By "human-specific" the project set to address the question of the relevance of experimental models for human health, at least in this specific setting of the neurodevelopmental domain. The mixture of chemicals prepared to examine alterations in neurodevelopment (termed in the project 'MixN') contains phthalates, BPA and fluorinated substances. The effects of exposure on the process of cell differentiation was tested in two timeframes representing acute exposure (for $48 \mathrm{~h}$ ) and chronic exposure (for 7 days). Both types of exposure were tested in five different concentrations of the mixture to determine the lowest level of concentration in which a molecular event is initiated. Determining the lowest level at which mixtures have effects is not the same as setting safety thresholds. However, if effects can be shown to initiate at real-life low concentrations, this means that single-substance regulation underestimates the risk for adverse effects.

The experimental setting was carried out according to the workflow below (Fig. 2):

The process described in Fig. 2 for NGN2 neurons was applied to the organoid and fetal brain tissues as well. After exposure of the cells, the next step consisted of 
Fig. 2 NGN2 experimental workflow, repeated for both acute- and chronic exposure (By kind permission of Nicolò Caporale, MD, PhD, IEO,

European Institute of Oncology IRCCS, Milan)

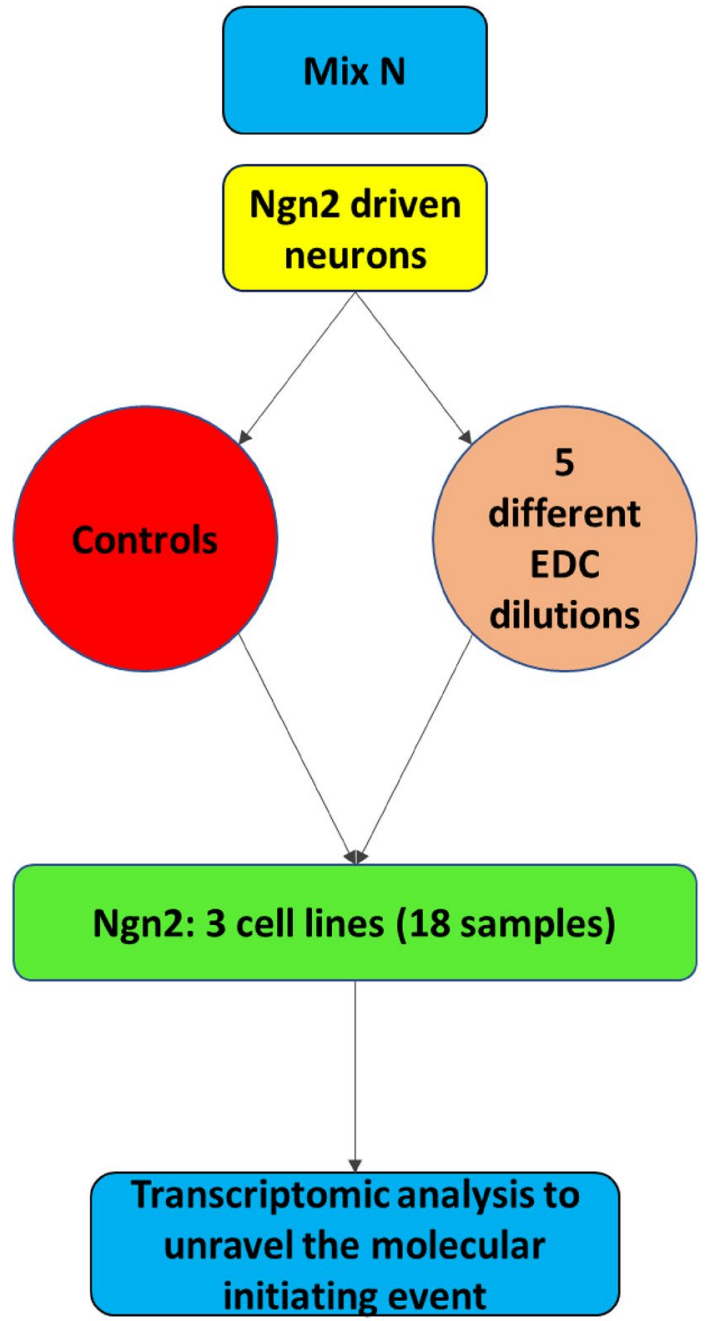

rendering meaningful the information derived from the affected biological material. This step represents the transformation of living entities (in this example, NGN2 neurons) perturbed by chemicals to the state of data. The transcriptome from these cellular models was sequenced and bioinformatically interpreted. The aim of this process was to identify the genes, whose expression (in terms of RNA transcribed from them) is differential in the models treated by exposure to MixN as compared with the control models. The bioinformatic analysis was meant to identify these differences with the highest statistical confidence possible. If the function of these differentially expressed genes can be linked in the literature to neurodevelopment, this means that exposure on the one side causes interference in gene behavior and connects to neurodevelopmental disorders such as autism and cognitive disabilities. To 
An unbiased method for the identification of genes affected by the compound mixtures

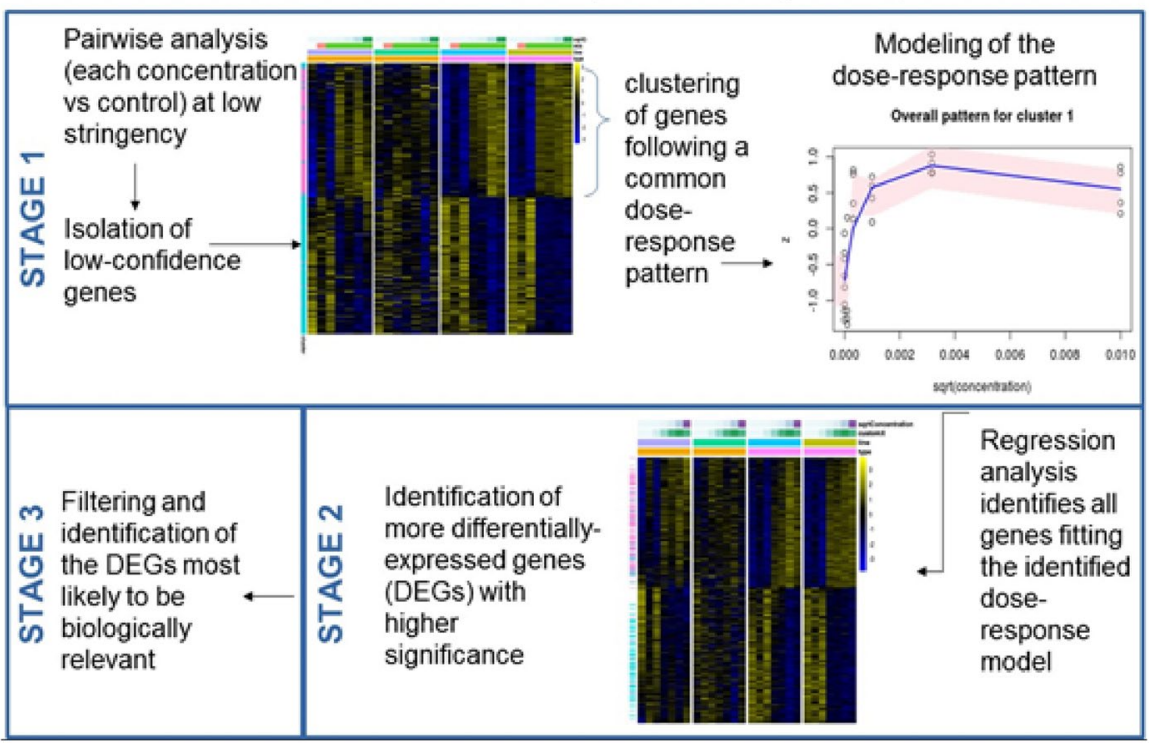

Fig. 3 Bioinformatic strategy for the interpretation of EDC exposure on neurodevelopment (By kind permission of Nicolò Caporale, MD, PhD, IEO, European Institute of Oncology IRCCS, Milan and Pierre-Luc Germain, PhD, D-HEST Institute for Neurosciences, ETH Zürich and Lab of Statistical Bioinformatics, University of Zürich; see also (Birgersson et al. 2017))

accomplish this, the bioinformatic and statistical analyses followed the strategy as depicted below (Fig. 3):

Briefly, the approach taken to identify the affected genes was to gradually filter them from the whole set of genes of NGN2 cells. The bioinformatic analysis started by interpreting concentrations of MixN as distinct groups and compare their effects with the control sample. This stage makes no prior assumptions as to which are the relevant genes nor what the response patterns would be. The result is a preliminary list of genes that will guide the subsequent attempt to identify the genes, the expression of which is affected by exposure to EDCs. From a total of thousands of genes of the NGN2 neural cells, the preliminary list contains just a few genes that are expressed across the five mixture concentrations. The next step consists of identifying patterns of the responses of genes to exposure, based on this set of genes: "The dose-response patterns showed dysregulation already at low concentrations, highlighting the significance of doses recapitulating human exposure" (Birgersson et al. 2017, p. 7). The differential expression values of the complete set of thousands of genes was then analyzed against each of these patterns. This step identified the complete set of genes which were differentially expressed due to exposure out of the whole set of genes of NGN2 cells with higher confidence. The results of this latter analysis were examined for biological associations of adverse health effects, discerned in existing literature (2017, pp. 6-7). 
As mentioned, the same process was performed using two additional neurodevelopmental models. These two models embodied again the attempt to approximate the real-life human neurological development in experiments as closely as possible. The first model consisted of neural cells cultured from fetal brain tissue. On the one hand, this model is the closest substitution for real-life nascent human brains, as it is taken from actual human tissue. It can thus be regarded as a 'gold-standard' on which to examine realistic exposures. On the other hand, because obtaining and handling these tissues poses ethical issues and their availability is inherently constrained, their role as a real-life experimental benchmark for regulatory purposes is limited. While NGN2 and fetal-originated neural cells are both two dimensional models, in line with a long-standing history of cell culture systems (Landecker 2010), the third model represents a transition to the currently most advanced attempt to simulate in vitro the architecture of developing cell populations of the human cortex (Farahany et al. 2018). If proven equivalent to the 'gold-standard' cultures directly sourced from human fetal cortices, organoids could thus have much greater experimental utility in the exploration of the effects of EDC mixtures since they are a self-renewable resource and as standard tools for toxicity testing by regulators and producers. Organoids can be understood as means for translating findings from the molecular to the regulatory scale by supporting a causal claim: if a neurodevelopmental response to exposure at very low concentrations of EDC mixtures can be demonstrated in models of the developing brain, this can be used to advance the need to regulate EDC mixtures as a class in itself, no matter how low the threshold of discerned effects actually is.

Moreover, the elusive effects of EDC mixtures (understood as non-linear, lowdose effects of multiple chemicals) could not be discerned if it were not for the arranged encounter of biological models with chemicals. This set-up was meant to model real-life exposure patterns - the widespread 'blanket' of exposure to numerous chemicals present at low concentrations. This encounter was a way to capture and represent molecular perturbations so as to turn them into credible bases for regulatory change, however distanced the regulatory scale may seem from the objects and the labor in the lab. The causal claim thus functions to facilitate the translation from the materiality of the molecular scale, to the discursiveness of the societal scale. This scale, in the end, requires that knowledge on the effects of EDCs is expressed in risk assessment terms. In this light, the regulatory scale was meant to accomplish two goals:

...EDC-MixRisk will further develop a systematic and transparent approach for evaluating, integrating and synthesizing complex datasets for EDCs and mixtures. With complex datasets we mean information derived from different levels of investigation - in particular in vitro and in vivo models and epidemiology. Such approach could also accelerate our capacity to generate the evidence linking environmental chemicals to adverse health impacts. Furthermore, in order to address the ethical and societal dimensions of the project, it will include a scholarly analysis of the ethical and societal implications raised by the project, grounded in the disciplines of bioethics, biolaw and science and technology studies (European Commission 2015, p. 133). 
In other words, the findings accumulated on the epidemiological and molecular scales were to be used to develop models for mixture risk assessment, offered later as means to improve EU chemical regulation. The models represented an additional step in trying overcome the causal ambiguity of EDCs and a more explicit type of scientific activism. One model that was developed concerned a framework for improved assessment of evidence on the effects of chemicals regarded as EDCs and considered as hazardous by the European Chemical Agency, using an approach called 'systematic review' (Vandenberg et al. 2016). The model evaluates evidence gained from various sources, mainly industry and academic studies. For example, when processing evidence for the chemical Triphenyl phosphate, the systematic review "...showed that for the first criterion of the IPCS/WHO definition (adverse effect), strong evidence exists for effects on the metabolism, in particular regarding the development of diabetes" (Ruden and Bui 2019, p. 4), and therefore, together with additional evidence, is likely to be an endocrine disruptor.

The second model reifies the epidemiological and experimental evidence of the project that confirmed that mixture have an adverse effect, into a statistical model that predicts the efficacy of future mixtures to be released to the market. The rationale behind this approach is that: "Since human exposure entails multiple EDCs in mixtures, the quantification of health effects associated with environmental mixtures is a critical goal for establishing environmental policy sufficiently protective of human health" (Bornehag et al. 2019, p. 2260). For this reason, the model takes a whole mixture approach "...based on an experimentally tested reference mixture and mixtures sufficiently similar to the reference mixture" $(2019$, p. 2260), in contrast to common models that are based on the sum of the effect of each chemical in the mixture (additive or concentration models). That is, the model takes the mixtures tested in the project as benchmarks, on the assumption that these mixtures represent common real-life exposures. It compares new mixtures to these benchmark mixtures.

As an attempt to affect real life, the project was mobilized towards an explicit purpose. This can be viewed as part of the trend characterizing European Commission Horizon 2020 funded projects and the Responsible Research and Innovation framework (Oudheusden 2014). However, in this case, science acted in a contested field where other formidable actors strive to shape EDC regulation. One of the final products of the project was therefore a policy brief which was circulated to EU decision makers, akin to what Frickel described as action-oriented promotional texts (2004, p. 85). In this text, the project advanced the basic argument according to which: "Current regulations of man-made chemicals systematically underestimate health risks associated with combined exposures to EDCs or potential EDCs" (Bergman et al. 2019, p. 2). On the basis of the findings, the project recommended that "regulatory requirements should take mixtures and combined exposures into account in all relevant EU chemicals and environment legislations" (2019, p. 2). This is an ambitious if unrealistic goal, but one that represents a sense of urgency conveyed in such framing texts. To close full circle with its overarching political goal, the project argued explicitly that: 
if the new mixture risk assessment methods and approaches were incorporated in existing legislations dealing with chemical mixtures ... these novel methods may significantly contribute to more relevant risk assessment and management by providing more reliable empirical information and better reflecting real life scenarios which in turn would alleviate the burden of disease and health expenditure attributed to EDC and benefit the wellbeing of future generations (2019, p. 5).

\section{Discussion}

In this paper we set out to understand how real-life exposure to multiple chemicals considered as endocrine disruptors is approached in a large-scale life-science enterprise, represented in the case of the EDC-MixRisk project. We demonstrated how the project engages with uncertainty on two main dimensions: that of real-life contingency of exposure to multiple chemicals simultaneously, and that of endocrine disruption more specifically. To facilitate the engagement with a problem of real-life exposure to multiple EDCs and their resultant adverse health effects, a mixture epistemology was pursued. Taking on these uncertainties resulted again in two sorts of scientific activism. First, the very engagement with mixtures of EDCs in a scientific project meant stepping into a politically contested field. For that purpose, the project was constructed from the bottom-up: from real-life exposure deduced from epidemiology through analytical chemistry, validated in experimental biology, to the EU policy scale. We demonstrated how this process took place by focusing on an example of a neurodevelopmental experiment. Second, based on its findings, actors in the project attempted to provide input to shape EU chemical regulation itself.

We argued that real-life contingency of exposure patterns and the uncertainty of EDCs had part on how the project was constructed. Attempting to approximate real life in experimentation sciences, for example through the use of human in vitro models such as cortical organoids, is part of a larger movement to use so-called 'realworld evidence' in the life sciences and biomedicine (Sherman et al. 2016; Beaulieu-Jones et al. 2019). However, constructing the project on uncertainty poses an internal contradiction. On the one hand, regulation is still founded on safety thresholds, and the EU criteria to identify substances as endocrine disruptors require that a causal relation between exposure and adverse effect be demonstrated through an endocrine pathway. The project responded to the question of thresholds by trying to discern the lowest concentration in which the real-life-inferred EDC mixtures show effects on experimental model. Yet, contingent real-life exposure and its potentiality in terms of instigating effect are what constitutes uncertainty (Hepler-Smith 2019; Langston 2014). This challenge stood at the heart of the project.

Still, a mixture approach allowed the project to look beyond the aggregate effects of single chemicals. The recognition of uncertainty, contingency and indeterminacy, and an acknowledgement of adversity and suffering caused by environmental exposure, consequently propelled scientific political action. In this sense, a mixture is performative: even if it is a mere representation of the world, it was harnessed as a vehicle for the achievement of certain political goals. The way that action has taken 
shape resembles previous attempts by scientific movement to arouse concern to the problems of chemical exposure and advocate for policy change (Frickel 2004). The EDC-MixRisk, therefore, represented a duality. It was science "as-usual" working on science-policy interfaces. It was not "miniscule" science, both for the sheer extent of the operation and for engaging with a global problem in the field of EU regulation (Shapiro 2015; Liboiron et al. 2018). In this sense, the project continued an established tradition in toxicological science, historically constructed vis-à-vis regulation (Boudia and Jas 2014). However, the project started from locating chemicals in the bodies of women (Daemmrich 2008) in a specific locality in Sweden. On that it built its claim to change the European single-substance risk assessment paradigm (Bergman et al. 2019). Coupled with its interdisciplinary structure and an underlying component of uncertainty, to an extent, it constituted an 'unusual' science. In historical perspective, this implies that such scientific configurations still occupy a significant place in acting in a polluted world.

The EDC-MixRisk project, as we have shown, parsed the problem of real-life exposure along the levels of human population, experimental biology and EU-wide chemical regulation. As represented in the project, real life was the exposed life out there, where women and their children, as representatives of the European population, bear the brunt of man-made chemicals. In the project, real-world evidence that came from the outside, from real lives, became incorporated into biostatistical and experimental scales and then processed as discursive output - the attempt to improve European chemical regulation. By positioning mixtures as the pivot of its epistemological assumptions, the project not only advanced 'mixture risk assessment' tools to improve chemical regulation, but also the recognition of chemical exposure indeterminacy in the public sphere, that nevertheless requires preemptive action. No less than localized action from below, this mode of scientific action brings to the fore and problematizes the context in which real life is experienced today: in a state of constant risk and ubiquitous exposure to EDCs. What was put at stake here, therefore, was the attempt to shape to technoscientific futures (Webster 2007): to relocate real-life chemical risks in the balance between the values of protection of the environment and human health, and a market-driven economy.

Acknowledgements We wish to thank the Editors of BioSocieties and the Reviewers for their helpful comments. We are indebted to the management and partners of the EDC-MixRisk Consortium for their contributions and collaboration. We are also grateful to Prof. Åke Bergman, Stockholm University, Nicolò Caporale, MD, PhD, High Definition Disease Modelling Lab: Stem Cell and Organoid Epigenetics, Department of Experimental Oncology, IEO, European Institute of Oncology IRCCS, Milan, Italy and Pierre-Luc Germain, PhD, also from the High Definition Disease Modelling Lab, European Institute of Oncology, currently at D-HEST Institute for Neurosciences, ETH Zürich and Lab of Statistical Bioinformatics, University of Zürich, for their kind permission to use the figures. Special thanks to Nicolò Caporale, Pierre-Luc Germain and Leah Even Chorev for their comments on drafts of this text.

Funding This project has received funding from the European Union's Horizon 2020 research and innovation programme under Grant Agreement No 634880.

Conflict of interest The authors confirm that they do not have any competing interests—intellectual or financial-in the research detailed in the manuscript. 
Ethical Approval The studies on which the research is based have been subject to appropriate ethical review and comply with EU and local ethical rules.

Open Access This article is licensed under a Creative Commons Attribution 4.0 International License, which permits use, sharing, adaptation, distribution and reproduction in any medium or format, as long as you give appropriate credit to the original author(s) and the source, provide a link to the Creative Commons licence, and indicate if changes were made. The images or other third party material in this article are included in the article's Creative Commons licence, unless indicated otherwise in a credit line to the material. If material is not included in the article's Creative Commons licence and your intended use is not permitted by statutory regulation or exceeds the permitted use, you will need to obtain permission directly from the copyright holder. To view a copy of this licence, visit http://creativecommons.org/licen ses/by/4.0/.

\section{References}

Alavian-Ghavanini, A., and J. Rüegg. 2018. Understanding Epigenetic Effects of Endocrine Disrupting Chemicals: From Mechanisms to Novel Test Methods. Basic \& Clinical Pharmacology \& Toxicology 122 (1): 38-45. https://doi.org/10.1111/bcpt.12878.

Amin, N.D., and S.P. Paşca. 2018. Building Models of Brain Disorders with Three-Dimensional Organoids. Neuron 100 (2): 389-405. https://doi.org/10.1016/j.neuron.2018.10.007.

Beaulieu-Jones, B.K., S. Finlayson, W. Yuan, et al. 2019. Examining the Use of Real-World Evidence in the Regulatory Process. Clinical Pharmacology \& Therapeutics. https://doi.org/10.1002/cpt.1658.

Beck, U. 2006. Living in the World Risk Society. Economy and Society 35 (3): 329-345.

Benford, R.D., and D.A. Snow. 2000. Framing Processes and Social Movements: An Overview and Assessment. Annual Review of Sociology 26 (1): 611-639. https://doi.org/10.1146/annur ev.soc.26.1.611.

Bergman, A., A.-M. Andersson, G. Becher, et al. 2013a. Science and Policy on Endocrine Disrupters must not be Mixed: A Reply to a "Common Sense" Intervention by Toxicology Journal Editors. Environmental Health 12 (1): 69. https://doi.org/10.1186/1476-069x-12-69.

Bergman, A., J.J. Heindel, S. Jobling, et al. 2013b. State of the Science of Endocrine Disrupting Chemicals-2012: An Assessment of the State of the Science of Endocrine Disruptors Prepared by a Group of Experts for the United Nations Environment Programme and World Health Organization. Geneva: United Nations Environment Programme and the World Health Organization.

Bergman, A., M. Jonsson, C. Ruden, et al. 2019. EDC-MixRisk: POLICY BRIEF. March. Stockholm. https://edcmixrisk.ki.se/wp-content/uploads/sites/34/2019/03/Policy-Brief-EDC-MixRisk-PRINT ED-190322.pdf.

Beronius, A., C. Rudén, H. Håkansson, et al. 2010. Risk to All or None?: A Comparative Analysis of Controversies in the Health Risk Assessment of Bisphenol A. Reproductive Toxicology 29 (2): 132146. https://doi.org/10.1016/j.reprotox.2009.11.007.

Birgersson, L., G. Borbely, N. Caporale, et al. 2017. From Cohorts to Molecules: Adverse Impacts of Endocrine Disrupting Mixtures. bioRxiv. https://doi.org/10.1101/206664.

Bopp, S.K., R. Barouki, W. Brack, et al. 2018. Current EU Research Activities on Combined Exposure to Multiple Chemicals. Environment International 120: 544-562. https://doi.org/10.1016/j.envin t.2018.07.037.

Bornehag, C.-G., S. Moniruzzaman, M. Larsson, et al. 2012. The SELMA Study: A Birth Cohort Study in Sweden Following More than 2000 Mother-Child Pairs. Paediatric and Perinatal Epidemiology 26 (5): 456-467.

Bornehag, C.-G., E. Kitraki, A. Stamatakis, et al. 2019. A Novel Approach to Chemical Mixture Risk Assessment-Linking Data from Population-Based Epidemiology and Experimental Animal Tests. Risk Analysis 39 (10): 2259-2271. https://doi.org/10.1111/risa.13323.

Boudia, S. 2014. Managing Scientific and Political Uncertainty: Environmental Risk Assessment in a Historical Perspective. In Powerless Science? Science and Politics in a Toxic World, ed. S. Boudia and N. Jas, 95-112. New York: Berghahn Books. 
Boudia, S., and N. Jas. 2014. Introduction: The Greatness and Misery of Science in a Toxic World. In Powerless Science? Science and Politics in a Toxic World, ed. S. Boudia and N. Jas, 1-26. New York: Berghahn Books.

Boudia, S., A.N.H. Creager, S. Frickel, et al. 2018. Residues: Rethinking Chemical Environments. Engaging Science, Technology, and Society 4: 165-178. https://doi.org/10.17351/ests2018.245.

Brickman, R., S. Jasanoff, and T. Ilgen. 1985. Controlling Chemicals: The Politics of Regulation in Europe and the United States. Ithaca, NY: Cornell University Press.

Calafat, A.M., X. Ye, L.-Y. Wong, et al. 2008. Exposure of the U.S. Population to Bisphenol A and 4-tertiary-Octylphenol: 2003-2004. Environmental Health Perspectives 116 (1): 39-44. https://doi. org/10.1289/ehp.10753.

Caporale, N., and G. Testa. 2019. At the Intersection of Epigenetics and Regeneration: An Analysis of the Experimental Outlook of Organoid Technology. In Epigenetics and Regeneration, ed. D. Palacios, 385-402. London: Academic Press. https://doi.org/10.1016/B978-0-12-814879-2.00017-0.

Carrico, C., C. Gennings, D.C. Wheeler, et al. 2015. Characterization of Weighted Quantile Sum Regression for Highly Correlated Data in a Risk Analysis Setting. Journal of Agricultural, Biological, and Environmental Statistics 20 (1): 100-120. https://doi.org/10.1007/s13253-014-0180-3.

Colborn, T., F.S. vom Saal, and A.M. Soto. 1993. Developmental Effects of Endocrine-Disrupting Chemicals in Wildlife and Humans. Environmental Health Perspectives 101 (5): 378-384.

Creager, A.N.H. 2018. Human bodies as chemical sensors: A history of biomonitoring for environmental health and regulation. Studies in History and Philosophy of Science Part A 70. Experiencing the Global Environment: 70-81. https://doi.org/10.1016/j.shpsa.2018.05.010.

Daemmrich, A. 2008. Risk Frameworks and Biomonitoring: Distributed Regulation of Synthetic Chemicals in Humans. Environmental History 13: 684-694.

Damstra, T. 2002. Potential Effects of Certain Persistent Organic Pollutants and Endocrine Disrupting Chemicals on the Health of Children. Journal of Toxicology: Clinical Toxicology 40 (4): 457-465. https://doi.org/10.1081/CLT-120006748.

Damstra, T., S. Barlow, A. Bergman, et al. (eds.). 2002. Global Assessment of the State-of-the-Science of Endocrine Disruptors. Geneva: World Health Organization.

Demeneix, B., and R. Slama. 2019. Endocrine Disruptors: From Scientific Evidence to Human Health Protection. PE 608.866, March. Brussels: European Parliament. https://doi.org/10.2861/802173.

DeRosa, C., P. Richter, H. Pohl, et al. 1998. Environmental Exposures that Affect the Endocrine System: Public Health Implications. Journal of Toxicology and Environmental Health, Part B 1 (1): 3-26. https://doi.org/10.1080/10937409809524541.

Dietrich, D. 2018. Synthetic EDCs at the present human exposure ARE NO RISK for human health. European Parliament, Brussels. https://www.europarl.europa.eu/cmsdata/140567/Daniel\%20Die trich\%20Presentation.pdf. Accessed 27 Jan 2020.

Dietrich, D.R., S. von Aulock, H. Marquardt, et al. 2013. Scientifically Unfounded Precaution Drives European Commission's Recommendations on EDC Regulation, While Defying Common Sense, Well-Established Science and Risk Assessment Principles. Toxicology in Vitro 27 (7): 2110-2114. https://doi.org/10.1016/j.tiv.2013.07.001.

Entman, R.M. 1993. Framing: Toward Clarification of a Fractured Paradigm. Journal of Communication 43 (4): 51-58.

European Commission. 2000. COMMUNICATION FROM THE COMMISSION on the precautionary principle. $\mathrm{COM}(2000) 1$ final. Brussels: European Commission.

European Commission. 2001. White Paper: Strategy for a future Chemicals Policy. COM(2001) 88 final, 27 February.

European Commission. 2015. Integrating Epidemiology and Experimental Biology to Improve Risk Assessment of Exposure to Mixtures of Endocrine Disruptive Compounds - EDCMixRisk'. European Commission.

European Commission. 2016a. Endocrine disruptors Overview. https://ec.europa.eu/health/endocrine_ disruptors/overview_en. Accessed 27 Jan 2020.

European Commission. 2016b. Executive Summary of the Impact Assessment. SWD(2016) 212 final, 15 June. Brussels: European Commission. https://ec.europa.eu/health/sites/health/files/endocrine_disru ptors/docs/2016_impact_assessment_annex_en.pdf. Accessed 28 Jan 2020.

European Commission. 2017. Commission Delegated Regulation (EU) 2017/2100 of 4 September 2017 setting out scientific criteria for the determination of endocrine-disrupting properties pursuant to Regulation (EU) No 528/2012 of the European Parliament and Council (Text with EEA relevance. 
). EU) 2017/2100. Available at: https://eur-lex.europa.eu/legal-content/EN/TXT/PDF/?uri=CELEX :32017R2100\&from=EN. Accessed 1 Oct 2018.

European Commission. 2019. Integrating Epidemiology and Experimental Biology to Improve Risk Assessment of Exposure to Mixtures of Endocrine Disruptive Compounds I EDC-MixRisk Project I H2020 | CORDIS I European Commission. https://cordis.europa.eu/project/id/634880. Accessed 31 Jan 2020.

European General Court. 2015. Judgment of the General Court (Third Chamber) of 16 December 2015-Sweden v Commission (Case T-521/14). https://curia.europa.eu/juris/document/ document.jsf?text $=\&$ docid $=182064 \&$ pageIndex $=0 \&$ doclang $=E N \&$ mode $=$ req $\&$ dir $=\&$ occ $=$ first \&part $=1 \&$ cid $=3049884$. Accessed 27 Jan 2020.

Eurostat. 2018. Chemicals production and consumption statistics - Statistics Explained. https://ec.europ a.eu/eurostat/statistics-explained/index.php?title=Chemicals_production_and_consumption_stati stics\#Total_production_of_chemicals. Accessed 17 April 2019.

Even Chorev, N. and G. Testa. 2019. D7.5 Whitepaper on EDCs and health risks. 30 April. Brussels: European Commission. https://ec.europa.eu/research/participants/documents/downloadPu blic?documentIds=080166e5c4e405a8\&appId=PPGMS. Accessed 16 Sept 2019.

Ewald, F. 2002. The Return of Descartes's Malicious Demon: An Outline of a Philosophy of Precaution. In Embracing Risk: The Changing Culture of Insurance and Responsibility, ed. T. Baker and J. Simon, 273-301. Chicago: The University of Chicago Press.

Farahany, N.A., H.T. Greely, S. Hyman, et al. 2018. The Ethics of Experimenting with Human Brain Tissue. Nature 556 (7702): 429. https://doi.org/10.1038/d41586-018-04813-x.

Frickel, S. 2004. Chemical Consequences: Environmental Mutagens, Scientist Activism, and the Rise of Genetic Toxicology. New Jersey: Rutgers University Press.

Gore, A.C., J. Balthazart, D. Bikle, et al. 2013. Policy Decisions on Endocrine Disruptors Should Be Based on Science Across Disciplines: A Response to Dietrich et al. Endocrinology. https://doi. org/10.1210/en.2013-1854.

Hepler-Smith, E. 2019. Molecular Bureaucracy: Toxicological Information and Environmental Protection. Environmental History 24 (3): 534-560. https://doi.org/10.1093/envhis/emy134.

Hine, C. 2007. Multi-sited Ethnography as a Middle Range Methodology for Contemporary STS. Science, Technology, \& Human Values 32 (6): 652-671. https://doi.org/10.1177/0162243907303598.

Jasanoff, S., and H.R. Simmet. 2017. No Funeral Bells: Public Reason in a 'Post-Truth' Age. Social Studies of Science 47 (5): 751-770. https://doi.org/10.1177/0306312717731936.

Kienzler, A., E. Berggren, J. Bessems, et al. 2014. Assessment of Mixtures-Review of Regulatory Requirements and Guidance. Luxemburg: European Commission, Joint Research Centre.

Kitraki, E., I. Nalvarte, A. Alavian-Ghavanini, et al. 2016. Effects of Pre- and Post-natal Exposure to Bisphenol A on the Stress System. Endocrine Disruptors 4 (1): e1184775. https://doi. org/10.1080/23273747.2016.1184775.

Kortenkamp, A. 2014. Low Dose Mixture Effects of Endocrine Disrupters and Their Implications for Regulatory Thresholds in Chemical Risk Assessment. Current Opinion in Pharmacology 19: 105111. https://doi.org/10.1016/j.coph.2014.08.006.

Krippendorff, K. 2018. Content Analysis: An Introduction to Its Methodology, 4th ed. Thousand Oaks, CA: Sage.

Laakso, J. 2016. Feedback from: Endocrine Society. F260, 27 July. Brussels: European Commission. https://ec.europa.eu/info/law/better-regulation/initiatives/ares-2016-3071834/feedback/F260_en?p_ $\mathrm{id}=854$. Accessed 27 Jan 2020.

Landecker, H. 2010. Culturing Life: How Cells Became Technologies. Cambridge, MA: Harvard University Press.

Langston, N. 2010. Toxic Bodies: Hormone Disruptors and the Legacy of DES. New Haven: Yale University Press.

Langston, N. 2014. Precaution and the History of Endocrine Disruptors. In Powerless Science? Science and Politics in a Toxic World, ed. S. Boudia and N. Jas, 29-45. New York: Berghahn Books.

Liboiron, M., M. Tironi, and N. Calvillo. 2018. Toxic Politics: Acting in a Permanently Polluted World. Social Studies of Science 48 (3): 331-349. https://doi.org/10.1177/0306312718783087.

Maharaj, N. 2016. Using Field Notes to Facilitate Critical Reflection. Reflective Practice 17 (2): 114-124. https://doi.org/10.1080/14623943.2015.1134472.

Mansfield, B. 2017. Folded Futurity: Epigenetic Plasticity, Temporality, and New Thresholds of Fetal Life. Science as Culture 26 (3): 355-379. https://doi.org/10.1080/09505431.2017.1294575. 
Marelli, L., and G. Testa. 2019. iPSC- and Organoid-Based Biomedicine at the Intersection of Epigenetics and Regeneration: Charting the Normative Contours of Emerging Biomedical Platforms. In Epigenetics and Regeneration, ed. D. Palacios, 493-509. London: Academic Press. https://doi. org/10.1016/B978-0-12-814879-2.00021-2.

Mukherjee, R. 2016. Toxic Lunch in Bhopal and Chemical Publics. Science, Technology, \& Human Values 41 (5): 849-875.

Murphy, M. 2006. Sick Building Syndrome and the Problem of Uncertainty: Environmental Politics, Technoscience, and Women Workers. Durham: Duke University Press.

Nash, L. 2008. Purity and Danger: Historical Reflections on the Regulation of Environmental Pollutants. Environmental History 13: 651-658.

Oreskes, N., and E.M. Conway. 2010. Merchants of Doubt: How a Handful of Scientists Obscured the Truth on Issues from Tobacco Smoke to Global Warming. New York: Bloomsbury Press.

Organisation for Economic Co-operation and Development. 2018. Adverse Outcome Pathways, Molecular Screening and Toxicogenomics. https://www.oecd.org/chemicalsafety/testing/adverse-outcomepathways-molecular-screening-and-toxicogenomics.htm. Accessed 28 Nov 2018.

van Oudheusden, M. 2014. Where are the Politics in Responsible Innovation? European Governance, Technology Assessments, and Beyond. Journal of Responsible Innovation 1 (1): 67-86. https://doi. org/10.1080/23299460.2014.882097.

Perakyla, A., and J. Ruusuvuori. 2018. Analyzing Text and Talk. In The SAGE Handbook of Qualitative Research, 5th ed, ed. N.K. Denzin and Y.S. Lincoln, 1163-1201. London: Sage.

Perkins, E.J., P. Antczak, L. Burgoon, et al. 2015. Adverse Outcome Pathways for Regulatory Applications: Examination of Four Case Studies with Different Degrees of Completeness and Scientific Confidence. Toxicological Sciences 148 (1): 14-25. https://doi.org/10.1093/toxsci/kfv181.

Ralph, N., M. Birks, and Y. Chapman. 2015. The Methodological Dynamism of Grounded Theory. International Journal of Qualitative Methods. https://doi.org/10.1177/1609406915611576.

Roberts EFS. 2017. Exposure. https://culanth.org/fieldsights/exposure. Accessed 15 Nov 2019.

Rowe Davis, F. 2008. Unraveling the Complexities of Joint Toxicity of Multiple Chemicals at the Tox Lab and the FDA. Environmental History 13: 674-683.

Ruden, C., and T. Bui. 2019. D6.4 Report on how to ensure workability of the IPCS definition of EDCs. 15 April. https://ec.europa.eu/research/participants/documents/downloadPublic?documentId $\mathrm{s}=080166 \mathrm{e}$ c49b271c\&appId=PPGMS. Accessed 29 Jan 2020.

Scholz, N. 2016. Setting criteria on endocrine disruptors: Follow-up to the General Court judgment. PE 581.986, Briefing, April. https://www.europarl.europa.eu/RegData/etudes/BRIE/2016/581986/ EPRS_BRI(2016)581986_EN.pdf. Accessed 28 Jan 2020.

Shapiro, N. 2015. ATTUNING TO THE CHEMOSPHERE: Domestic Formaldehyde, Bodily Reasoning, and the Chemical Sublime. Cultural Anthropology 30 (3): 368-393. https://doi.org/10.14506/ ca30.3.02.

Sherman, R.E., S.A. Anderson, G.J. Dal Pan, et al. 2016. Real-World Evidence-What Is It and What Can It Tell Us? New England Journal of Medicine 375 (23): 2293-2297. https://doi.org/10.1056/ NEJMsb1609216.

Solecki, R., A. Kortenkamp, Å. Bergman, et al. 2016. Scientific Principles for the Identification of Endocrine-Disrupting Chemicals: A Consensus Statement. Archives of Toxicology 91: 1001-1006. https ://doi.org/10.1007/s00204-016-1866-9.

Tarrow, S.G. 2011. Power in Movement: Social Movements and Contentious Politics, 3rd ed. Cambridge, UK: Cambridge University Press.

The European Parliament and The Council. 2009. Regulation (EC) No 1107/2009 of the European Parliament and of the Council of 21 October 2009 concerning the placing of plant protection products on the market and repealing Council Directives 79/117/EEC and 91/414/EEC. https://eur-lex.europ a.eu/legal-content/EN/TXT/?uri=CELEX:32009R1107. Accessed 28 Jan 2020.

The European Parliament and The Council. 2012. Regulation (EU) No 528/2012 of the European Parliament and of the Council of 22 May 2012 concerning the making available on the market and use of biocidal products. https://eur-lex.europa.eu/legal-content/EN/TXT/PDF/?uri=CELEX:32012R0528 $\&$ from $=$ EN. Accessed 27 Jan 2020.

Vandenberg, L.N., R. Hauser, M. Marcus, et al. 2007. Human Exposure to Bisphenol A (BPA). Reproductive Toxicology 24 (2): 139-177. https://doi.org/10.1016/j.reprotox.2007.07.010.

Vandenberg, L.N., T. Colborn, T.B. Hayes, et al. 2012. Hormones and Endocrine-Disrupting Chemicals: Low-Dose Effects and Nonmonotonic Dose Responses. Endocrine Reviews 33 (3): 378-455. 
Vandenberg, L.N., M. Ågerstrand, A. Beronius, et al. 2016. A Proposed Framework for the Systematic Review and Integrated Assessment (SYRINA) of Endocrine Disrupting Chemicals. Environmental Health 15 (74): 1-19. https://doi.org/10.1186/s12940-016-0156-6.

Vogel, D. 2012. The Politics of Precaution: Regulating Health, Safety, and Environmental Risks in Europe and the United States. Princeton, NJ: Princeton University Press.

Vogel, S.A. 2008. From 'the Dose Makes the Poison' to 'the Timing Makes the Poison': Conceptualizing Risk in the Synthetic Age. Environmental History 13: 667-673.

Vogel, S.A. 2009. The Politics of Plastics: The Making and Unmaking of Bisphenol A 'Safety'. American Journal of Public Health 99 (S3): S559-S566.

Vos, J.G., E. Dybing, H.A. Greim, et al. 1999. CSTEE Opinion on Human and Wildlife Health Effects of Endocrine Disrupting Chemicals, with Emphasis on Wildlife and on Ecotoxicology Test Methods. March. https://www.minambiente.it/sites/default/files/archivio/allegati/interferenti_endocrini/rappo rto_cstee_1999_en.pdf. Accessed 27 Jan 2020.

Vos, J.G., E. Dybing, H.A. Greim, et al. 2000. Health Effects of Endocrine-Disrupting Chemicals on Wildlife, with Special Reference to the European Situation. Critical Reviews in Toxicology 30 (1): 71-133. https://doi.org/10.1080/10408440091159176.

Webster, A. 2007. Crossing Boundaries: Social Science in the Policy Room. Science, Technology, \& Human Values 32 (4): 458-478.

Webster, A. 2012. Introduction: Bio-Objects: Exploring the Boundaries of Life. In Bio-Objects: Life in the 21st Century, ed. N. Vermeulen, S. Tamminen, and A. Webster, 1-10. Farnham, UK: Ashgate Publishing.

Whaley, P., M. Agerstrand, Å. Bergman, et al. 2016. Open letter in response to the redrafted criteria for identification and regulation of endocrine disrupting chemicals, under the PPP and Biocides Regulations. 16 November. https://policyfromscience.com/wp-content/uploads/2016/11/Second-Scien tists-Letter-on-EDC-Criteria-FINAL.pdf. Accessed 27 Jan 2020.

Yin, R.K. 2014. Case Study Research: Design and Methods, 5th ed. London: Sage.

Zhang, Y., C. Pak, Y. Han, et al. 2013. Rapid Single-Step Induction of Functional Neurons from Human Pluripotent Stem Cells. Neuron 78 (5): 785-798. https://doi.org/10.1016/j.neuron.2013.05.029.

Publisher's Note Springer Nature remains neutral with regard to jurisdictional claims in published maps and institutional affiliations.

Nadav Even Chorev is a post-doctoral fellow at the European Institute of Oncology, Milan, Italy, and a member of the High Definition Disease Modelling Lab: Stem Cell and Organoid Epigenetics. He is a sociologist, Science and Technology Studies scholar and an IT practitioner.

Giuseppe Testa A three times ERC awardee, is Full Professor of Molecular Biology at the University of Milan, Head of the Centre for Neurogenomics of the Human Technopole and Director of the High Definition Disease Modelling Lab at the European Institute of Oncology. He successfully pursued a parallel career as practicing life scientist and scholar in Bioethics and Science and Technology Studies. 